\title{
The Evolutionary Roots of Sociality
}

To Olaf Breidbach, who loved sociality

Abstract: Evolution has led to the emersion of various forms of life through a Darwinian mechanism, which implies a "competition" for natural resources and, hence, selection. However, it was clear that "cooperation" has also played a crucial role, because it has operated since the beginning of life on our planet. In particular, cooperation has been crucial for the emerging of sociality in a little group of species, among pluricellular organisms. Albeit this occurred in different modalities, the population involved acts as a "superorganism". Sociality is also widespread in several mammals (apes, elephants and dolphins) and these societies can survive only if conflicts among individuals are settled through behaviours that allow the reconciliation between members of the community. Human beings have been the subject of similar mechanisms, but in a specific moment, culture overlapped those biological processes, thanks to the development of our intellectual faculties.

\section{The Evolution of Living Organisms: Competition versus Cooperation}

The evolution of life appears to be marked by unpredictable events whose outcome is not always expected, according to a modality that is defined 'contingency'. Evolution has led, however, to the emersion of various forms of life, even if ca. $99 \%$ of them went extinct. Nevertheless, Earth seems to spring up of living organisms. At present, there is an estimated number of ca. 1,750,000 species, but they could be more than 10 million.

The best explanation of this wonderful phenomenon has been offered by Charles R. Darwin in his masterpiece The origin of species by natural selection, published in 1859 (Darwin 1872). The underlying mechanism is simple. In a population of individuals differing for some characters, the environment performs a sorting-selection process of the best adapted individuals, which can then reproduce and spread ('adaptationism'). Obviously, this mechanism implies a 'competition' for natural resources, and, since selection occurs when resources are limited, the fittest individual tends to prevail.

During the $19^{\text {th }}$ century, this aspect was emphasized even for questionable purposes, such as in the case of the 'Social Darwinism'. Nevertheless, Darwin already understood that an explanation fully based on competition was not com-

Ә OpenAccess. ( 2021 Angelo Vianello, published by De Gruyter. (cc) BY-NC-ND This work is licensed under the Creative Commons Attribution-NonCommercial-NoDerivatives 4.0 International License. 
pletely satisfying. In fact, this is not in line with some notable examples of sociality, exhibited by ants and honeybees, where collaboration or, better, a 'cooperation' is widespread.

However, the competitive, conflictual description of the history of life became so dominant that the poet William Tennyson, could speak of "Nature, red in tooth and claw". This interpretation, in an up-to-date version, is still supported by Neo-Darwinists and, in particular, by Richard Dawkins, the author of the famous book The Selfish Gene, in which he states that genes, and their perpetuation, are at the core of the evolutionary process (Dawkins 1976). On the other hand, this view is challenged by other scientists, defined Naturalists, who adopted a multifactorial approach leading to a new vision named 'Extended Synthesis'. Albeit recognizing the value and relevance of Darwinism, they propose that the latter must be integrated by other mechanisms (Pigliucci Müller 2010). Cooperation plays a crucial role among these mechanisms, because it has operated since the beginning of life on planet earth, so that Martin A. Nowak in his brilliant book, Supercooperators, is entitled to say: "I propose that 'natural cooperation' be included as a fundamental principle to bolster those laid down by Darwin. [...] Cooperation makes evolution constructive and open-ended" (Nowak - Highfield 2012).

\section{Cooperation: From Molecules to Organisms}

A first incredible example of cooperation is offered, at the molecular level, by hemoglobin, the blood protein transporting oxygen. This protein is built up by four sub-units, each of them capable of fixing a molecule of oxygen. When a molecule of oxygen binds to the first sub-unit, this bond facilitates the entry of a second oxygen molecule to another sub-unit and so on for the third and fourth, because the affinity for oxygen progressively increases. On the contrary, myoglobin does not exhibit this property, being built up by a single polypeptide. The message is simple: the benefit of cooperation is precluded to selfish individuals and they must accept a lower efficiency.

In addition, this example reveals a second important phenomenon that is widespread in nature and is known as 'emergence'. This term identifies a property that emerges in complex systems, albeit being absent in the components of the complex. As seen before, in hemoglobin - composed by four sub-units (proteins) - emerges a higher efficiency of transporting oxygen with respect to myoglobin, formed by only one sub-unit (protein).

However, it is at the cellular level that cooperation deploys all its potential. Prokaryotes - unicellular organisms without a nucleus, included in the domains 
of Bacteria and Archaea and evolved 3,5-3,7 billion years ago -, feed themselves by phagocytosis; in other words, a bigger cell 'eats' the smaller: mors tua vita mea. Yet from this struggle for survival, an event - a transition, using the term introduced by John Maynard-Smith and Eörs Szathmàry - arose and allowed the emergence of eukaryotic organisms, cells with a true nucleus (Eukarya) (Maynard-Smith - Szathmáry 2009). This transition happened through a mechanism, known as 'endosymbiosis', suggested by Lynn Margulis. In short, aerobic bacteria, after being incorporated by phagocytosis, instead of being digested as food, started to live together with the host, in a relationship called 'mutualistic symbiosis'. This process gave rise to mitochondria, organelles involved in respiration. Similarly, chloroplasts, where photosynthesis takes place in plants, are the result of a phagocytosis, without success, with a cyanobacterium (Margulis Sagan 1967).

Another crucial transition led to the multicellular organisms (Metazoans). In this case the tendency of isolated cells to cooperate prevailed. This event took place in the Cambrian Period (ca. 542 billion years ago) when, in an apparently short period of time, a myriad of living organisms appeared; more importantly, the structural plans of all Metazoans appeared at that time (Gould 1990). Their fossils, found in sedimentary rocks, from a deposit known as Burgess Shale (British Columbia - Canada), were discovered by Charles Doolittle Walcott in 1909. The relevance of this incredible transition, defined Cambrian explosion by Simon Conway-Morris, was fully caught by Stephen J. Gould, who said: "the subsequent history of animal life amounts to little more than variations on anatomical themes established during the Cambrian explosion within five million years" (Gould 1990).

Among the many records from this deposit, re-classified by Conway-Morris, two are worth mentioning here: Trilobites from which insects evolved, and Pikaia gracilens, a little cordate, which, presumably, represents the ancestor of all vertebrates, apes and hominids included.

The success of colonial organisms and then of pluricellular organisms, depended mainly on the capacity of cells to establish relationships with each other. When the cells begun to cooperate and to differentiate, the tissues arose, allowing for the formation of organs and, finally, of organisms. This was possible because cells, which are able to cooperate with success, are plastic variants of the same genotype, where the term plasticity refers to the capacity of the genotype to express different forms (different phenotypes). In other words, the cell seems to partially renounce to its identity to reach a superior objective, depending on the relationships among several cells. Tissues and the primordial colonies were likely the target of a 'group selection', whereby the group that better cooperates prevails on the ones that are less cooperative (Wilson 2012). 
Apparently, a kind of path towards increasing complexity seems to have taken place. However, this interpretation is partly misleading for at least two reasons. First, the simplest organisms still rule the biosphere; e.g. bacteria, formed by one or few cell(s) (colonies) without nucleus, are the most widespread organisms. Second, the history of life, from Cambrian to current days, has been 'punctuated' by huge catastrophes, that confirm the role of contingency in the evolution of life. This surprising discovery was made by David Raup and collaborators, who showed that in the last 500 million years at least five mass extinctions occurred, which, in some cases, caused the extinction of $95 \%$ of the living organisms (Raup 1994). Nevertheless, the remaining 5\% were able to start a new "adaptive radiation": the flowering of new living forms. In particular, the extinction that occurred in the Cretacean (ca. 65 million years ago) accelerated the decline of dinosaurs, that, at that time, were the true dominators of the biosphere. This change endorsed the rise of mammals and, much later, also that of Homo sapiens, our species, through a non-linear evolutionary trajectory.

\section{The Emergence of Sociality: Superorganisms}

Sociality emerged in a little group of species, among pluricellular organisms; according to Edward O. Wilson, this, through different modalities, allowed the conquest of our planet. Wilson underlines the concept of 'superorganism', which is appropriate for honeybees, ants, wasps and termites; they are the result of a slow process of co-evolution with the environment in which they were living.

To describe the evolution of these complex biological systems, which can be appointed as eusocial (Wilson 2012), Wilson describes four possible steps. The first involves the formation of groups inside a heterogeneous population. This can occur by various modalities, the most common of which is represented by the cohesion of familiar groups. The second step involves the casual acquisition of characters favoring sociality. A typical example is offered by the nursing of the brood within the nest. These features are frequently acquired by cooptation of characters that originally performed a different function - through a mechanism named 'exaptation', already conceived by Charles R. Darwin as pre-adaptation -, and then re-defined by Elisabeth Vrba e Stephen J. Gould (Gould - Vrba 1986). The third step is based on accumulation, always accidental, of genetic and epigenetic characters that may increase eusociality. This can happen both as a result of casual mutations, or through the acquisition of such characters from immigrating populations already carrying these genes. All these evolutionary novelties are then selected by the environment through a mechanism known as "group selection", which - in a hierarchical vision, named "multilevel selec- 
tion" (Gould - Vrba 1982) - operates along individual selection. Due to the selection at this level, the groups including cooperative individuals prevail on the less cooperative groups.

Group selection was first proposed in 1962 by Vero Wynne-Edwards. Initially this theory was heavily criticized, and a strong debate is still going on among evolutionary biologists. Neo-Darwinists prefer "kin selection", a mechanism through which an altruistic trait is selected if it can benefit the relatives of the individual carrying the respective gene (Hamilton 1964). John B. S. Haldane synthesized this concept with the following sentence: "I am prompt to sacrifice myself to save two brothers, or eight cousins". The gene-centric logic which is implicit in this reasoning is quite obvious.

\section{Sociality at Work: Examples from Superorganisms}

Before considering some examples of how sociality has been declined in superorganisms, it is useful to acknowledge our tendency to constantly consider the human behavior as a template for understanding the life of animals, thus indulging ourselves in a misleading anthropocentrism. This is important because a serious research, not affected by any bias, is essential to unravel some structural aspects of animal societies that could be of great interest for better understanding human societies.

Social species include many examples in which the interactions (links) among individuals play a crucial role in defining their behavior. A classic example is offered by the building of nest by social insects like honeybees (Nazzi 2016).

Looking at the honeybees' nest, we recognize the extraordinary features of this structure and its adequacy to the purpose for which it is built. The honeycomb is composed by thousands of hexagonal wax prisms, forming a structure with great mechanic resistance and built with a minimum amount of material.

However, how is the honeybees' nest constructed? It is interesting to note that the building process follows a scheme that is completely different from the one used by man to produce his artifacts. While an engineer first conceives an idea and then realizes that project, honeybees do not act in such a manner. Instead, they carry out a limited number of stereotyped actions, according to a principle defined "stigmergy", first described by the French biologist PierrePaul Grassé. Through the juxtaposition of small wax scales, following those 
few simple rules, a very complex structures can arise, with no individual knowing $a$ priori the aspect that this structure will assume when completed.

A second beautiful example, revealing the extraordinary results of cooperation and sociality in honeybees, can be observed during swarming (Nazzi 2016).

In springtime, the honeybee colonies can split to form new smaller groups called swarms. On this occasion, while inside the hive a new queen is developing, the old one, together with half of the mother colony, flies off the hive for landing at a short distance, where the bees remain until the scouts find a convenient site for establishing a new nest. With this objective, some specialized honeybees explore the territory to search for a cavity matching some specific requirements, such as a sufficient internal volume, an adequate entry and so on. When scout bees return to the swarm, they communicate the localization of the new potential nest to the other bees using the famous waggle dance, indicating both the direction and distance of the potential nesting site they have found. The better the characteristics of the potential nest, the greater the 'enthusiasm' that the scout bee puts in the dance, which results in a higher number of cycles performed while dancing. By doing this, the scout tries to convince as many members of the colony as possible. This incredible example, suggests that honeybees, when taking an important decision, dialogue with their companions to reach a consensus among the majority of members of their colony, in a process strongly resembling how decisions are taken by human beings in democratic societies.

Thomas D. Seeley, who widely studied this process, suggests that a similar scheme may well be implemented in the social life of our species (Seeley 2010). We must go beyond digital platforms and intermittent surveys, to promote public meetings instead, at least once a year, to discuss about the main strategies for the promotion and administration of the society. This method is already exploited in some cities of the East Cost of United Sates through the so-called town meetings.

It is always delicate and sometime misleading to establish fascinating parallelisms by comparing the behavior of animal species with ours. However, if a serious research is correctly performed, without any bias, very useful new information can be extrapolate. As seen above, also superorganisms may teach us something, even if their behavior is mainly dictated by genes. But animal species, mammals in particular, seem to go beyond this rigid scheme, because in some cases they manifest forms of sociality based on primitive forms of culture. 


\section{Not Only Superorganisms: Sociality in Mammals}

This very important topic has been studied in detail by several ethologists and psychologists. In particular, two major figures, Frans de Waal and Michael Tomasello, described in some of their excellent books, the phylogenetic origin of sociality in several mammal species and its impact on human behavior. Actually, mammals offer many interesting examples, particularly our distant cousins: the apes (Waal 1997; Tomasello 2014, and 2016).

Primate societies can survive only if conflicts among individuals are settled through behaviors that allow the reconciliation among the members of the community; therefore, this subject is worth our attention. An illuminating example is offered by Frans de Waal (Waal 1997), who described the behavior of two fourmonths-old females of rhesus macaques, named Oatly e Napkin. It once happened that, while the two little monkeys were struggling for fun, Napkin's aunt arrived and immobilized Oatly. Napkin took advantage of this situation and jumped over Oatly in order to bite her. After a short battle, the two monkeys separated. Later, Oatly went, without hesitation, towards Napkin, who was sitting with his is aunt, and started to groom her (in primates, this behavior is very important for maintaining their social relations). As a result of Oatly's initiative, Napkin turned towards her and hugged her. Immediately, the aunt also joined the two monkeys in a big hug.

It is important to underline that these behaviors are not completely innate but are the result of learning from others who have already put into practice this behavior. This incredible result was further confirmed by another wonderful experiment, again performed by de Waal (Waal 1997). He put two groups of monkeys in the same cage: ursine colobus and rhesus macaques. The choice of these two species was related to the fact that ursine are more tolerant and sociable than rhesus, which have rigid hierarchies. More importantly, ursine reconcile more frequently than rhesus.

At the beginning of the experiment the two groups constantly stood at the opposite corners of the cage; rhesus shouted at ursine that, essentially, ignored them. However, gradually, ursine, perhaps attracted by the rhesus' tail, started to groom them. This behavior became so frequent that, after five months, the two groups lived together, forming a compact cluster during the night. Hence, we should strive for peace, if we want to live together since it does not make any difference how diverse we are: diversity is at the 'core' of all living organisms.

Apes, elephants and dolphins offer further examples of social behaviors including cases where an individual helps a conspecific that happens to be in trou- 
ble (Waal 2017). The first report of a dolphin helping another dates back to 1954 and occurred off the coast of Florida. On that occasion, two dolphins helped an injured one by sustaining its body at the surface of water so that it could breath. This is a clear example of aimed help. But, in the case of dolphins, generosity may be extended also to other species. A stunning example was witnessed by a biologist working on marine mammals in California in her autobiography (Bearzi 2012). One day she was following a little group of dolphins feeding on a sardine flock, not too far from the coastline. At a certain point, she saw a dolphin suddenly swimming on its own towards the open sea, promptly followed by its companions. Intrigued by this strange behavior, the biologist decided to follow the dolphins with her boat, until, some kilometers away from the coast, dolphins stopped near a human body that was floating inanimate in water. The person was rescued and transported to the hospital just in time; it turned out to be a young girl, who had decided to commit suicide by swimming into the open sea... where she was saved by a group of dolphins.

This story is even more impressive considering recent news of human beings look the other way while other humans drown in the sea escaping from war or hunger just a few meters from salvation.

At this point a question becomes imperative: "Are we sure that there is anything we can learn from animals?”.

My answer is firm and clear: yes, we can for at least two reasons. First, as already conceived by Charles R. Darwin, all living organisms are linked together in the tree of life; we therefore share genes with bacteria, fishes, amphibian reptiles, etc. - in other words, we have a common history. In addition, "mirror neurons" - discovered by Giacomo Rizzolatti and co-workers - were firstly identified in apes and then in humans. These neurons are very important, because they are involved in the emergence of empathy, that precedes altruistic behaviors which, I think, are at the "core" of sociality (Rizzolatti - Sinigaglia 2006). ${ }^{1}$

\section{Sociality in Humans}

During their evolution, human beings have been the subject of the mechanisms dealt with before. However, at a specific moment, culture overlapped those biological processes thanks to the development of our intellectual faculties. This

1 On the debates concerning "mirror neurons" and "empathy" see also the Chapter "'Das Wissen von fremden Ichen' Mindreading und Einfühlung unter Berücksichtigung von Theodor Lipps” by F. Fabbianelli in this volume. 
likely happened after our last exit from Africa, ca. 72,000 years ago, just after risking an extinction caused by a climatic change affecting Earth 77,000 years ago (Marean 2010).

The first hominids, hunters-gatherers, having a "social intelligence", soon begun to produce various types of instruments and to control the fire - perhaps already 1,8 millions of years ago with Homo erectus -, fact that, according to Richard Wrangham, would be at the origin of our human nature (Wrangham 2019). Cooked flesh was crucial to increase the volume of our brain, from which the intellectual faculties typical of our mind depend on. This was possible because our encephalon, that had a volume of $420 \mathrm{~cm}^{3}$ in Australopithecines, our precursors, reached ca. 1,200 $\mathrm{cm}^{3}$ in Homo sapiens, also thanks to a diet richer of proteins (Tattersall 2013). In addition, fire favored the gathering of our ancestors and thus the formation of the first social groups.

In addition, Homo sapiens, but also Homo neanderthalensis, started to display a symbolic thought, as demonstrated at its peak in the wonderful pictures from the caves of Chauvet, Lascaux, (France) and Altamira (Spain). But, first of all, the feature that distinguishes us from the other animals as human beings is verbal language. According to Ian Tattersall, this capacity co-evolved with symbolic thought; according to its speed this process occurred through a non-Darwinian mechanism of cooptation-exaptation. However, as Tattersall states: "the absence of long-term fine-tuning of our cognitive systems in our evolutionary past helps to explain why our decision-making processes are typically so messy" (Tattersall 2017). This is why "our behaviors are frequently so irrational, so self-destructive and so short-termist”. Besides this bad news, Tattersall himself offers another encouraging remark when he says: "The good news here is that, at least biologically speaking, we human beings really do have a substantial measure of free will, at least to the extent that how we behave is not dictated by our biology" (Tattersall 2017). This is very important for us, but it implies that "this endows us with a special responsibility for our actions both individually and as a species" (Tattersall 2017).

These compelling considerations lead us to two fundamental conclusions. On the one hand, we have to be aware that our social groups, conceived as "adaptive complex systems", are linked to the history of all living organisms included in the tree of life, where it is possible to observe the first signs of sociality; on the other hand, our cognitive capacities and our language are the strongest instruments we have to improve our society with the final aim to save our species and the biosphere. This is the only possibility we have to guarantee a future to humanity. Hereby, the thought of two important philosophers of the last century can be very important. Hans Jonas introduced the concept of responsibility as a logical consequence of our free will (Jonas 2012). Martin Buber said: "man only 
later rises in the struggle of the spirit with a turning to men as persons [...] but from the distinctiveness of his relation to things and to living beings" (Buber 1961).

\section{Acknowledgements}

I thank very much Francesco Nazzi for some important suggestions and the critical reading of the manuscript. I also thank Eleonora Zancani for the revision of the English language.

\section{Bibliography}

Bearzi M. (2012): Dolphin Confidential: Confessions of a Field Biologist. Chicago-London: The University of Chicago Press.

Buber, M. (1961): Between Man and Man. London: Collins.

Darwin, C. (1872): On the Origin of Species by Means of Natural Selection, or the

Preservation of Favoured Races in the Struggle for Life; 6th edn. London: John Murray.

Dawkins, R. (1976): The Selfish Gene. New York: Oxford University Press.

Gould, S.J. (1990): Wonderful Life: The Burgess Shale and the Nature of History. New York et al.: W. W. Norton \& Company.

Gould, S.J. - Vrba, E.S.V.R. (1982): “Exaptation: A Missing Term in the Science of Form”. In: Paleobiology 8, 4-15.

Gould, S.J. - Vrba, E.S.V.R. (1986): "The Hierarchical Expansion of Sorting and Selection: Sorting and Selection Cannot Be Equated”. In: Paleobiology 12, 217-228.

Hamilton, W.D. (1964): “The Genetical Evolution of Social Behaviour”. In: J. Theor. Biol. 7, 1-16.

Jonas, H. (2012): Das Prinzip Verantwortung: Versuch einer Ethik für die technologische Zivilisation. Frankfurt am Main: Suhrkamp Verlag.

Marean, C. (2010): "When the Sea Saved Humanity”. In: Sci. Am. 303, 55-61.

Margulis Sagan, L. (1967): “On the Origin of Mitosing Cells”. In: J. Theor. Biol. 14, 225-IN6.

Maynard Smith, J. - Szathmáry, E. (2009): The Origins of Life: From the Birth of Life to the Origin of Language. Oxford: Oxford Univ. Press.

Nazzi, F. (2016): "The Hexagonal Shape of the Honeycomb Cells Depends on the Construction Behavior of Bees". In: Scientific Reports 2016, 6, 28341.

Nowak, M.A. - Highfield, R. (2012): SuperCooperators: Altruism, Evolution, and Why We Need Each Other to Succeed. New York: Free Press - Simon and Schuster.

Pigliucci, M - Müller, G.B. (2010): Evolution, the extended synthesis, Cambridge, Massachusetts - London, MIT Press.

Raup, D.M. (1994): "The Role of Extinction in Evolution". In: Proc. Natl. Acad. Sci. U. S. A. 91, $6758-6763$.

Rizzolatti, G. - Sinigaglia, C. (2006): So quel che fai: Il cervello che agisce e i neuroni specchio. Milano: Raffaello Cortina. 
Seeley, T.D. (2010): Honeybee Democracy. Princeton: Princeton University Press.

Tattersall, I. (2013): Masters of the Planet: The Search for Our Human Origins. New York: St. Martin's Griffin.

Tattersall, I. (2017): The Thinking Primate / Il primate pensante. Udine: Forum Editrice. Tomasello, M. (2016): A Natural History of Human Morality. Cambridge, Massachusetts: Harvard University Press.

Tomasello, M. (2014): A Natural History of Human Thinking. Cambridge, Massachusetts London: Harvard University Press.

Waal, F.D. (2017): Are We Smart Enough to Know How Smart Animals Are? New York: W W Norton \& Co Inc.

Wilson, E.O. (2012): The Social Conquest of Earth. New York: W.W. Norton \& Company, 2012.

Wrangham, R. (2019): The Goodness Paradox: How Evolution Made Us Both More and Less Violent. London: Profile Books.

Waal, F.D. (1997): Good Natured: The Origins of Right and Wrong in Humans and Other Animals. Cambridge, Massachusetts: Harvard Univ. Press. 
